\title{
Transcriptional responses of Arabidopsis thaliana plants to As (V)
} stress

\author{
Jason M Abercrombie ${ }^{1}$, Matthew D Halfhill ${ }^{2}$, Priya Ranjan ${ }^{1}$, Murali R Rao1, \\ Arnold M Saxton ${ }^{3}$, Joshua S Yuan ${ }^{1}$ and C Neal Stewart Jr*1
}

\author{
Address: ${ }^{1}$ Department of Plant Sciences, University of Tennessee, 2431 Joe Johnson Blvd., Knoxville, TN 37996-4561, USA, 2 Biology Department, \\ St. Ambrose University, 518 West Locust St., Davenport, IA 52803, USA and ${ }^{3}$ Department of Animal Science, University of Tennessee, 2505 River \\ Dr., Knoxville, TN 37996-4561, USA \\ Email: Jason M Abercrombie - jabercro@utk.edu; Matthew D Halfhill - HalfhillMatthewD@sau.edu; Priya Ranjan - pranjan@utk.edu; \\ Murali R Rao - mraghave@utk.edu; Arnold M Saxton - asaxton@utk.edu; Joshua S Yuan - syuan@utk.edu; C \\ Neal Stewart* - nealstewart@utk.edu \\ * Corresponding author
}

Published: 6 August 2008

BMC Plant Biology 2008, 8:87 doi:1 0.1 | 86/147|-2229-8-87
Received: 16 October 2007

Accepted: 6 August 2008

This article is available from: http://www.biomedcentral.com/I47/-2229/8/87

(c) 2008 Abercrombie et al; licensee BioMed Central Ltd.

This is an Open Access article distributed under the terms of the Creative Commons Attribution License (http://creativecommons.org/licenses/by/2.0), which permits unrestricted use, distribution, and reproduction in any medium, provided the original work is properly cited.

\begin{abstract}
Background: Arsenic is toxic to plants and a common environmental pollutant. There is a strong chemical similarity between arsenate $[\mathrm{As}(\mathrm{V})]$ and phosphate $(\mathrm{Pi})$. Whole genome oligonucleotide microarrays were employed to investigate the transcriptional responses of Arabidopsis thaliana plants to As (V) stress.

Results: Antioxidant-related genes (i.e. coding for superoxide dismutases and peroxidases) play prominent roles in response to arsenate. The microarray experiment revealed induction of chloroplast Cu/Zn superoxide dismutase (SOD) (at2g28/90), Cu/Zn SOD (atlg08830), as well as an SOD copper chaperone (at Ig 12520). On the other hand, Fe SODs were strongly repressed in response to As (V) stress. Non-parametric rank product statistics were used to detect differentially expressed genes. Arsenate stress resulted in the repression of numerous genes known to be induced by phosphate starvation. These observations were confirmed with qRT-PCR and SOD activity assays.

Conclusion: Microarray data suggest that $A s(V)$ induces genes involved in response to oxidative stress and represses transcription of genes induced by phosphate starvation. This study implicates As $(V)$ as a phosphate mimic in the cell by repressing genes normally induced when available phosphate is scarce. Most importantly, these data reveal that arsenate stress affects the expression of several genes with little or unknown biological functions, thereby providing new putative gene targets for future research.
\end{abstract}

\section{Background}

Arsenic (As) is a toxic metalloid found ubiquitously in the environment [1] and is classified as a human carcinogen [2]. Currently, the US Environmental Protection Agency declares arsenic as the highest priority hazardous sub- stance found at contaminated sites in the United States (see Availability and requirements section for URL). Naturally high levels of arsenic in drinking water have caused major human health problems in the United States, China, Argentina, Taiwan, and most notably in Bangla- 
desh and India where tens of millions of people have been affected $[3,4]$. Arsenic is highly toxic at low concentrations, therefore drinking water safety standards were lowered from 50 to $10 \mu \mathrm{g} / \mathrm{L}$ in the U.S. [5].

Plants typically encounter arsenic in the anionic forms of arsenate [As (V)] and arsenite [As (III)], both of which have different cytotoxic effects [6]. As (III) reacts with the sulfhydryl groups of enzymes and proteins, thereby inhibiting cellular function and resulting in death [7]. Alternatively, As (V) is an analog of the macronutrient phosphate, so it competes with phosphate for uptake in the roots, as well as in the cytoplasm where it might disrupt metabolism by replacing phosphate in ATP to form unstable ADP-As [8]. Once taken up by the roots, arsenate is reduced to a more highly toxic species, arsenite, which is subsequently detoxified via soluble thiols such as glutathione and/or phytochelatins (PCs) and transported for vacuolar sequestration [9]. PCs are low molecular weight thiolate peptides of the general structure ( $\gamma$-Glu-Cys $)_{n}$-Gly $(n=2-11)$ and are synthesized from glutathione by the constitutively present phytochelatin synthase [10]. Both arsenate and arsenite efficiently induce the production of PCs in plants [11], however it is believed since arsenate has no affinity for the sulfhydryl groups in PCs, As (V) is reduced in the cytoplasm, resulting in As(III)-PC complexes [6]. Glutathione and PCs have been reported to form As(III)-tris-thiolate complexes in Brassica juncea upon exposure to $\mathrm{As}(\mathrm{V})$ [9]. Therefore, PC synthesis causes a depletion of cellular glutathione, resulting in a decreased capacity to quench reactive oxygen species (ROS) [12].

Phytoremediation has emerged as an alternative technology for removing toxic metals from contaminated soils and groundwater. The potential for phytoremediation to be an effective means of removing arsenic from contaminated sites has been demonstrated in hyperaccumulators of the Pteris genus [13-15] and may be enhanced by a better understanding of plant transcriptional responses to arsenic. Many plant studies have demonstrated the direct involvement of thiol-containing molecules (glutathione, phytochelatins, etc.) in arsenic detoxification, however more robust approaches (i.e. microarrays) should help clarify how arsenic affects plant physiological processes on a global scale. The goals of our study were to test our hypothesis that many genes would be differentially expressed in response to arsenate stress and to identify genes as putative players in As $(\mathrm{V})$ detoxification using Arabidopsis as a model. In this paper, we investigate the transcriptional responses to As (V) in Arabidopsis thaliana using oligonucleotide microarrays. Our results demonstrate that As $(\mathrm{V})$ stress strongly induces $\mathrm{Cu} / \mathrm{Zn}$ superoxide dismutase (SOD) activity, but represses the production of $\mathrm{Fe}$ SODs. Our microarray data also suggest the involve- ment of other antioxidant genes, various transcription factors, tonoplast proteins, and proteins associated with cell wall growth. Of particular interest, we report that As (V) stress represses numerous genes induced by Pi starvation. We discuss the physiological implications of these findings, and suggest new avenues for research of arsenic metabolism in plants.

\section{Results \\ Root growth under As (V) stress}

Arsenate exposure resulted in reduced Arabidopsis root growth and branching (Figure 1). Exposure of $50 \mu \mathrm{M}$ As (V) resulted in significantly reduced Arabidopsis root growth (Figure 1C). In addition to known relevant physiological data, the exposure study was used to determine suitable As (V) exposure for the microarray study. We noted no seed germination effects with regard to arsenate treatments, notably at $100 \mu \mathrm{M}$, the arsenate concentration used for transcriptomics experiments.

\section{Gene ontology for genes affected by As (V)}

Forty-six genes were induced by As (V) treatment (i.e., exceeded a fold-change threshold of 1.5 and met a significance criteria of $P<0.001$; FDR $<1 \%$ ) as indicated by microarray analysis. The largest functional categories affected included unknown function, hydrolase, and antioxidant activity. Other functional categories affected by As (V) included genes with transferase, kinase, lyase, transporter, and binding activity [see Additional file 1; Table 1]. Alternatively, 113 genes were repressed by As (V) (i.e. exceeded a fold-change threshold of -1.5 and met a significance criteria of $P<0.001$; FDR $<\% 1$ ), with unknown function, hydrolase, and binding activity representing the largest categories. Genes with transporter, kinase, transferase, and transcriptional regulator activity were also repressed by As (V) [see Additional file 1; Table 2]. Differentially expressed As (V)-induced and -repressed genes are listed below (Table 1 and Table 2, respectively) and complete lists of all genes affected by As (V) stress are also included as additional files [see Additional files 3 and 4]. Most interestingly, it was discovered that As (V) stress repressed transcription of many genes involved in the phosphate starvation response, and also repressed several transcriptional factors. Several genes involved in oxidative stress were also highly modulated in response to As.

\section{Superoxide dismutases}

SODs represented the highest ranked of both significantly induced as well as repressed genes in response to As (V) stress (Tables 1 and 2), therefore these genes presented logical primary targets for the validation of our microarray data. Results demonstrated 4.57-fold induction of a chloroplast $\mathrm{Cu} / \mathrm{Zn}$ SOD (at2g28190), 2.41-fold induction of a $\mathrm{Cu} / \mathrm{Zn}$ SOD (at1g08830), as well as a 3.16-fold induction of an SOD copper chaperone (at1g12520). Alternatively, 


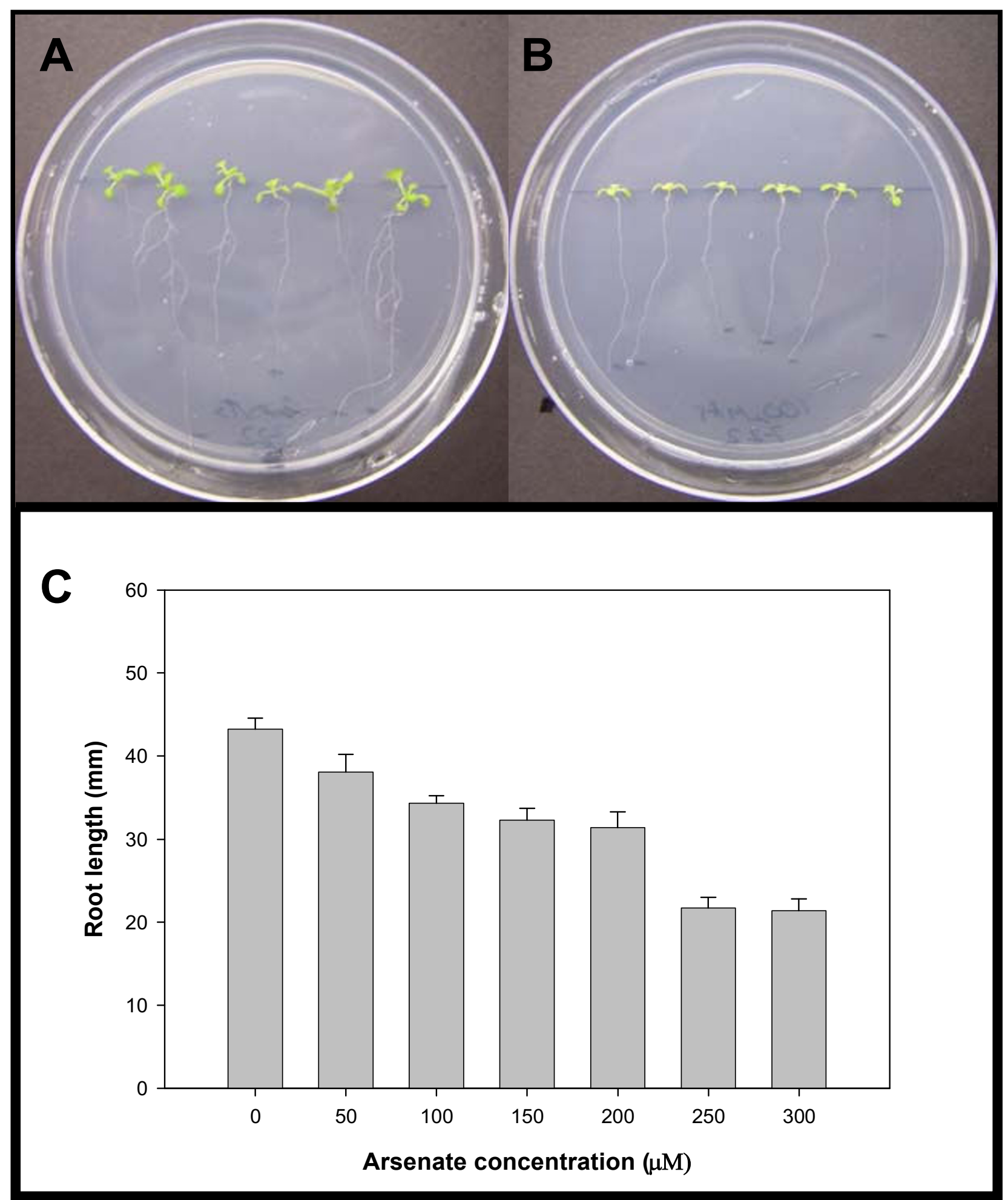

Figure I

Phenotype of arsenate stress in Arabidopsis. Representative Arabidopsis thaliana "Columbia" plants grown for 10 days on MS medium containing either (Panel A) $0 \mu \mathrm{M}$ As (V) or (Panel B) $100 \mu \mathrm{M}$ arsenate. C. Histogram of root length vs. As (V) concentration. 
Table I: Gene ontology based on molecular function for induced genes of arsenic-treated Arabidopsis thaliana Columbia plants.

\begin{tabular}{|c|c|c|c|c|}
\hline Molecular function & Gene ID & Locus & FC & RP \\
\hline \multirow[t]{8}{*}{ Antioxidant activity } & Peroxiredoxin $\mathrm{Q}$ & at3g26060 & 1.53 & 151.4 \\
\hline & peroxidase & at5g64100 & 2.50 & 7.3 \\
\hline & peroxidase & at $\lg 05250$ & 1.90 & 49.0 \\
\hline & peroxidase 57 (PER57) (P57) (PRXR I0) & at5gl7820 & 1.68 & 56.6 \\
\hline & peroxidase & at $\lg 05240$ & 2.05 & 16.5 \\
\hline & superoxide dismutase [Cu-Zn], chloroplast & at $2 \mathrm{~g} 28190$ & 4.57 & 2.3 \\
\hline & superoxide dismutase [Cu-Zn], (SODCC) (CSDI) & at $\lg 08830$ & 2.41 & 8.6 \\
\hline & superoxide dismutase copper chaperone & at $\lg \mid 2520$ & 3.16 & 5.2 \\
\hline \multirow[t]{2}{*}{ Metal ion binding } & metallothionein-like protein IA, (MT-IA) & at lg07600 & 1.67 & 41.9 \\
\hline & ferredoxin, chloroplast & at $\lg 10960$ & 1.53 & 95.6 \\
\hline \multirow[t]{2}{*}{ Kinase activity } & leucine-rich repeat transmembrane protein kinase & at $3 g 24240$ & 1.59 & 63.2 \\
\hline & Cyclin-dependent protein kinase & at5g61650 & 1.64 & 66.9 \\
\hline Oxygen binding & non-symbiotic hemoglobin I (HBI) (GLBI) & at2gl6060 & 1.59 & 94.2 \\
\hline \multirow[t]{5}{*}{ Hydrolase activity } & ATPase, BadF/BadG/BcrA/BcrD-type family & at $\lg 30540$ & 1.62 & 75.5 \\
\hline & myrosinase-associated protein & at $\lg 54010$ & 1.54 & 90.5 \\
\hline & myrosinase-associated protein & at $\lg 54000$ & 1.68 & 47.6 \\
\hline & xyloglucan:xyloglucosyl transferase & at4g37800 & 1.61 & 72.0 \\
\hline & glycosyl hydrolase family I protein & at3g09260 & 1.67 & 50.8 \\
\hline Isomerase activity & peptidyl prolyl cis-trans isomerase & at3g62030 & 1.64 & 53.1 \\
\hline \multirow[t]{2}{*}{ Lyase activity } & ribulose bisphosphate carboxylase small chain $2 \mathrm{~B}$ & & & \\
\hline & ribulose bisphosphate carboxylase small chain 3B & & & \\
\hline Alcohol dehydrogenase activity & alcohol dehydrogenase (ADH) & at $\lg 77 \mid 20$ & 1.74 & 46.5 \\
\hline Nitrate reductase activity & nitrate reductase I (NRI) & at $\lg 77760$ & 1.77 & 41.8 \\
\hline Sulfate reduction & 5'-adenylylsulfate reductase (APR3) & at4g21990 & 1.53 & 112.1 \\
\hline \multirow[t]{13}{*}{ Molecular function unknown } & Photoassimilate-responsive protein & at3g54040 & 1.59 & 112.1 \\
\hline & Expressed protein & at $\lg 09310$ & 1.67 & 63.1 \\
\hline & Replication protein & At5g35260 & 1.62 & 975.3 \\
\hline & Hypothetical protein related to GB:AADI533I & at2g06480 & 1.58 & 81.6 \\
\hline & DREPP plasma membrane polypeptide-related & at5g44610 & 1.54 & 106.5 \\
\hline & Pentatricopeptide repeat-containing protein & at $\lg 07590$ & 1.62 & 74.6 \\
\hline & Meprin and TRAF domain-containing protein & at5g26280 & 1.60 & 70.8 \\
\hline & Expressed protein & at4g39675 & 1.72 & 86.0 \\
\hline & C2-domain-containing protein & at4gl5740 & 1.76 & 42.7 \\
\hline & Expressed protein & at $\lg 09340$ & 1.62 & 78.4 \\
\hline & Late embryogenesis abundant 3 family protein & at4g02380 & 1.67 & 52.1 \\
\hline & Bet v I allergen family protein & at lg24020 & 1.54 & 98.4 \\
\hline & Universal stress protein & at3g03270 & 1.98 & 19.7 \\
\hline \multirow{2}{*}{ Transporter activity } & Plasma membrane intrinsic protein 2B (PIP2B) & at2g37170 & 1.70 & 43.3 \\
\hline & Tonoplast intrinsic protein gamma & at2g36830 & 1.53 & 104.2 \\
\hline Glutathione transferase activity & Glutathione S-transferase GST20; Tau class & at lg78370 & 1.68 & 53.5 \\
\hline Cell wall structure & Glycine-rich protein & at2g05510 & 4.31 & 2.4 \\
\hline RNA binding & Pumilio/Puf RNA-binding domain-containing protein & At $\lg 78160$ & 1.60 & 67.7 \\
\hline Stress response & Drought-responsive protein $(\mathrm{Di} 2 \mathrm{I})$ & at4gI5910 & 1.67 & 69.6 \\
\hline Electron transport & Cytochrome B56I family protein & at5g38360 & 1.56 & 97.9 \\
\hline Amino acid biosynthesis & asparagine synthetase 2 & at5g65010 & 1.74 & 65.1 \\
\hline Carbonic anhydrase activity & Carbonic anhydrase I, chloroplast & at3g0I500 & 1.67 & 51.0 \\
\hline
\end{tabular}

RP, rank products; FC, fold change. Only genes upregulated above I.5-fold and meeting a significance criteria of $P<0.00 I$ and FDR of I\% are shown. Rank products analysis reveals that most significantly induced genes display the lowest RP value.

Fe SOD (at4g25100) transcripts were downregulated in response to arsenic stress (-5.17-fold change). These findings were confirmed with quantitative RT-PCR (qRT-PCR) (Table 3).

Based upon our observations of transcript-level changes in SOD gene expression, we performed a nondenaturing PAGE enzyme assay of superoxide dismutase activity [16] to assess whether the observed specific changes in SOD transcript correlated with enzyme activity. This method enables the distinction between the three SOD isoenzymes found in Arabidopsis (CuZnSOD, FeSOD, and MnSOD) by using inhibitors of specific SODs. Gels were preincubated with KCN, which inhibits CuZn SOD, as well as $\mathrm{H}_{2} \mathrm{O}_{2}$, which inhibits both $\mathrm{CuZn} \mathrm{SOD}$ and $\mathrm{Fe}$ SOD. MnSOD is resistant to both inhibitors (Figure 2). 
Table 2: Gene ontology based on molecular function for selected repressed genes of arsenic-treated Arabidopsis thaliana Columbia plants.

\begin{tabular}{|c|c|c|c|c|}
\hline Molecular function & Gene ID & Locus & FC & RP \\
\hline Catalase activity & catalase 3 (SEN2) & at $\lg 20620$ & -1.59 & 191.7 \\
\hline \multirow[t]{3}{*}{ Peroxidase activity } & peroxidase & at3g49|20 & -1.77 & 165.3 \\
\hline & peroxidase & at5g64I20 & -1.84 & 123.2 \\
\hline & cationic peroxidase & at4g25980 & -1.52 & 333.1 \\
\hline \multirow[t]{5}{*}{ Oxidoreductase activity } & superoxide dismutase $[\mathrm{Fe}]$, chloroplast & at $4 g 25100$ & -5.17 & 1.7 \\
\hline & lipoxygenase & at $\lg 72520$ & -2.41 & 242.9 \\
\hline & FAD-binding domain-containing protein & at $\lg 26380$ & -1.50 & 293.0 \\
\hline & cytochrome $\mathrm{p} 45083 \mathrm{BI}$ & at4g3I 500 & $-1.7 \mid$ & 142.3 \\
\hline & auxin-responsive family protein & at5g35735 & -1.59 & 156.4 \\
\hline \multirow[t]{10}{*}{ Metal ion binding } & germin-like protein & at5g39160 & $-|.5|$ & 319.7 \\
\hline & germin-like protein & at5g39190 & -2.13 & 27.3 \\
\hline & calcium-binding EF hand family protein & at lg76650 & -2.00 & 50.4 \\
\hline & C2-domain containing protein & at4g34I50 & -1.53 & 313.4 \\
\hline & touch-responsive protein/calmodulin-related & at2g4II00 & -1.64 & 137.9 \\
\hline & ferritin I (FER I) & at5g01600 & -1.78 & 83.0 \\
\hline & ferritin 4 & at3g56090 & -1.52 & 201.0 \\
\hline & zinc finger $(\mathrm{C} 2 \mathrm{H} 2$ type) protein & at3g46090 & $-|.5|$ & 191.2 \\
\hline & zinc finger $(\mathrm{C} 2 \mathrm{H} 2$ type) protein & at3g46080 & -1.59 & 178.8 \\
\hline & zinc finger ( $\mathrm{C} 3 \mathrm{HC} 4$ type) protein & at5g27420 & -1.75 & 82.2 \\
\hline \multirow[t]{15}{*}{ Hydrolase activity } & lipase class 3 family protein & at $\lg 02660$ & -1.56 & 218.8 \\
\hline & invertase/pectin methylesterase family protein & at5g62360 & -1.75 & 85.0 \\
\hline & protein phosphatase $2 \mathrm{C}$ & at2g30020 & -1.52 & 237.4 \\
\hline & phosphoric monoester hydrolase & at $\lg 73010$ & -3.01 & 7.0 \\
\hline & acid phosphatase type 5 (ACP5) & at3gl 17790 & -1.62 & 290.7 \\
\hline & phosphoric monoester hydrolase & at $\lg 17710$ & -1.88 & 118.6 \\
\hline & glycosyl hydrolase family 17 protein & at3g55430 & -1.53 & 201.2 \\
\hline & glycosyl hydrolase family 17 protein & at4g3। I 40 & -1.71 & 248.5 \\
\hline & glycosyl hydrolase family 17 protein & at4g19810 & -1.96 & 99.2 \\
\hline & glycosyl hydrolase family 36 protein & at5g20250 & -1.52 & 201.8 \\
\hline & xyloglucan endotransglucosylase/hydrolase & at4g30280 & -1.63 & 172.2 \\
\hline & xyloglucan endotransglucosylase/hydrolase & at4gl4130 & -2.00 & 47.9 \\
\hline & xyloglucan endotransglucosylase/hydrolase & at5g57560 & -1.68 & 97.3 \\
\hline & nudix hydrolase homolog 4 & at $\lg \mid 8300$ & -1.54 & 215.9 \\
\hline & MERI-5 endo-xyloglucan transferase & at4g30270 & -1.96 & 45.6 \\
\hline \multirow[t]{4}{*}{ Protein binding } & calmodulin-binding family protein & at4g33050 & -1.78 & 88.6 \\
\hline & ankyrin repeat family protein & at5g45II0 & -1.58 & 252.0 \\
\hline & mitochondrial substrate carrier family protein & at4g24570 & -1.50 & 260.2 \\
\hline & polygalacturonase inhibitory protein & at5g06860 & $-1.9 \mid$ & 65.0 \\
\hline Chitin binding & hevein-like protein (HEL) & at3g04720 & -1.53 & 499.9 \\
\hline Carbohydrate binding & legume lectin family protein & at3gl 6530 & -2.03 & 37.8 \\
\hline Sugar binding & curculin-like lectin family protein & at $\lg 78830$ & -1.64 & 138.3 \\
\hline ATP binding & ATP-dependent Clp protease ATP-binding subunit & at5g51070 & $-|.5|$ & 188.7 \\
\hline Jasmonic acid synthesis & allene oxide cyclase & at3g25760 & -1.54 & 279.6 \\
\hline \multirow[t]{2}{*}{ Peptidase activity } & vacuolar processing enzyme gamma & at4g32940 & -1.65 & 117.1 \\
\hline & subtilase family protein & at $\lg 32970$ & -1.91 & 81.1 \\
\hline \multirow[t]{2}{*}{ Ligase activity } & v-box domain-containing protein & at2g35930 & -1.63 & 205.5 \\
\hline & asparagine synthetase $I$ & at3g47340 & -1.74 & 75.5 \\
\hline \multirow[t]{3}{*}{ Transferase activity } & glutathione S-transferase (GSTF6); phi class & at lg02930 & -2.10 & 62.9 \\
\hline & glutathione S-transferase (GSTF7); phi class & at lg02920 & -2.88 & 7.6 \\
\hline & branched-chain amino acid amino transferase 2 & at $\lg 10070$ & -1.60 & 113.8 \\
\hline Nutrient reservoir activity & patatin & at2g26560 & -1.81 & 84.8 \\
\hline Kinase activity & serine/threonine protein kinase 19 & at3g08720 & -1.55 & 249.8 \\
\hline \multirow{6}{*}{ Molecular function unknown } & hypothetical protein no ATG start & at3g09922 & -2.15 & 33.6 \\
\hline & expressed protein & at2g25510 & -1.99 & 96.9 \\
\hline & expressed protein no ATG start & at5g03545 & -2.72 & 16.8 \\
\hline & expressed protein & at5g42530 & -2.01 & 147.4 \\
\hline & expressed protein & at4g3I 570 & -2.21 & 45.6 \\
\hline & expressed protein & at $\lg 69890$ & -1.73 & 79.9 \\
\hline
\end{tabular}


Table 2: Gene ontology based on molecular function for selected repressed genes of arsenic-treated Arabidopsis thaliana Columbia plants. (Continued)

\begin{tabular}{|c|c|c|c|c|}
\hline & expressed protein & at5g20790 & -2.33 & 32.7 \\
\hline & expressed protein & at2g04460 & -1.73 & 190.5 \\
\hline & VQ motif-containing protein & at $2 g 22880$ & -1.83 & 57.3 \\
\hline & glycine-rich protein & at $\lg 07 \mid 35$ & -1.53 & 167.4 \\
\hline & glycine-rich protein & at3g04640 & -1.81 & 73.9 \\
\hline & glycine-rich protein & at2g05540 & -1.85 & 47.9 \\
\hline & glycine-rich protein & at2g05380 & -1.59 & 146.7 \\
\hline & integral membrane family protein & at4g15610 & -1.58 & 139.7 \\
\hline & gibberellin-responsive protein & at $\lg 22690$ & -1.88 & 51.5 \\
\hline & gibberellin-regulated protein (GASAI) & at lg75750 & -1.70 & 93.7 \\
\hline & dehydrin (RABI8) & at5g66400 & -1.70 & 81.1 \\
\hline & unknown protein - similar to glycosyltransferase & at2g4 640 & -1.54 & 185.8 \\
\hline & patatin-like protein 8 & at4g29800 & -1.52 & 198.7 \\
\hline & phosphate-responsive protein & at5g64260 & -1.52 & 221.0 \\
\hline & phosphate-responsive protein & at $\lg 35140$ & -1.58 & 131.5 \\
\hline & similar to LITAF-domain containing protein & at5g 13190 & -1.54 & 293.4 \\
\hline \multirow{8}{*}{ Transcription factor activity } & DRE-binding protein & at $\lg 12610$ & -1.74 & 116.8 \\
\hline & AP2 domain-containing transcription factor & at4g34410 & -2.01 & 50.4 \\
\hline & zinc finger $(\mathrm{C} 2 \mathrm{H} 2$ type $)$ protein & at3g46090 & -1.51 & 191.2 \\
\hline & zinc finger $(\mathrm{C} 2 \mathrm{H} 2$ type) protein & at3g46080 & -1.59 & 178.8 \\
\hline & WRKY family transcription factor 33 & at2g38470 & -1.63 & 157.9 \\
\hline & WRKY family transcription factor 53 & at4g23810 & -1.55 & 278.3 \\
\hline & WRKY family transcription factor 40 & at lg80840 & -1.88 & 70.9 \\
\hline & NAC domain-containing protein & at5g08790 & -1.53 & 238.7 \\
\hline \multirow[t]{4}{*}{ Senescence-related } & senescence-associated family protein & at5g66040 & -1.55 & 164.0 \\
\hline & senescence/dehydration-associated protein & at2gl 7840 & -1.60 & 256.9 \\
\hline & senescence-associated protein (SENI) & at4g35770 & -1.59 & 123.9 \\
\hline & SRG3 (senescence-related gene 3) & at3g02040 & -2.65 & 11.0 \\
\hline Transporter activity & MATE efflux family protein & at $\lg 61890$ & -1.80 & 108.3 \\
\hline Galactolipid biosynthesis & monogalactosyldiacylglycerol synthase type $C$ & at $2 g 11810$ & -1.78 & 130.5 \\
\hline Electron transport & cytochrome p450 family 94 subfamily B & at3g48520 & -1.56 & 249.8 \\
\hline Guanosine tetraphosphate metabolism & RSH 2 (RELA-SPOT HOMOLOG) & at3g 14050 & -1.52 & 188.7 \\
\hline $\mathrm{N}$-terminal protein myristoylation & band 7 family protein & at3g0I 290 & -1.54 & 253.4 \\
\hline
\end{tabular}

RP, rank products; FC, fold change. Only genes upregulated above -1.5 -fold and meeting a significance criteria of $P<0.00 \mathrm{I}$ and $F D R$ of $I \%$ are shown. Rank products analysis reveals that most significantly repressed genes display the lowest RP value.

Table 3: Comparison of microarray expression data (significance criteria of $P<0.001$ and FDR of I\%) with RT-PCR data from arsenatetreated Arabidopsis thaliana.

\begin{tabular}{|c|c|c|c|c|}
\hline \multirow[t]{2}{*}{ Gene id } & \multirow{2}{*}{ gene name } & \multirow[t]{2}{*}{ ratio $^{a}$} & \multicolumn{2}{|c|}{$\Delta \Delta \mathrm{Ct}^{\mathrm{b}}$} \\
\hline & & & Day 3 & Day 10 \\
\hline at2g28190 & $\mathrm{Cu} \mathrm{Zn}$ SOD (CSD2) & 4.57 & 3.06 & 3.77 \\
\hline at $\lg 12520$ & $\mathrm{Cu} \mathrm{Zn}$ SOD Cu chaperone & 3.16 & 3.14 & 2.44 \\
\hline at lg08830 & $\mathrm{Cu} Z \mathrm{Zn}$ SOD (CSDI) & 2.41 & 4.54 & 2.96 \\
\hline at4g25100 & Fe SOD (SODB) & -5.17 & -2.49 & -1.80 \\
\hline at $\lg 73010$ & phosphoric monoester hydrolase & -3.01 & -6.70 & -2.97 \\
\hline at5g20790 & expressed protein & -2.33 & -4.85 & -2.32 \\
\hline at2gl| 810 & MGDG synthase type $C$ & -1.78 & -1.50 & -2.44 \\
\hline at3g|7790 & acid phosphatase type 5 (ACP5) & -1.62 & -4.65 & -4.44 \\
\hline at $\lg 17710$ & phosphoric monoester hydrolase & -1.88 & -9.57 & -3.00 \\
\hline at2g04460 & expressed protein & -1.73 & -6.04 & -2.80 \\
\hline at3g08720 & serine/threonine protein kinase 19 & -1.55 & -5.58 & -1.82 \\
\hline at3g02040 & senescence-related gene 3 (SRG3) & -2.65 & -5.12 & -1.85 \\
\hline at5g61650 & P-type cyclin & 1.64 & -5.60 & -3.39 \\
\hline
\end{tabular}

a Microarray data (linear fold-change)

b RT-PCR data ( $\triangle \Delta C t$ values) Arabidopsis Actin was used as a reference gene (see Materials and Methods)

$P$ values for RT-PCR data were $<0.05$. 


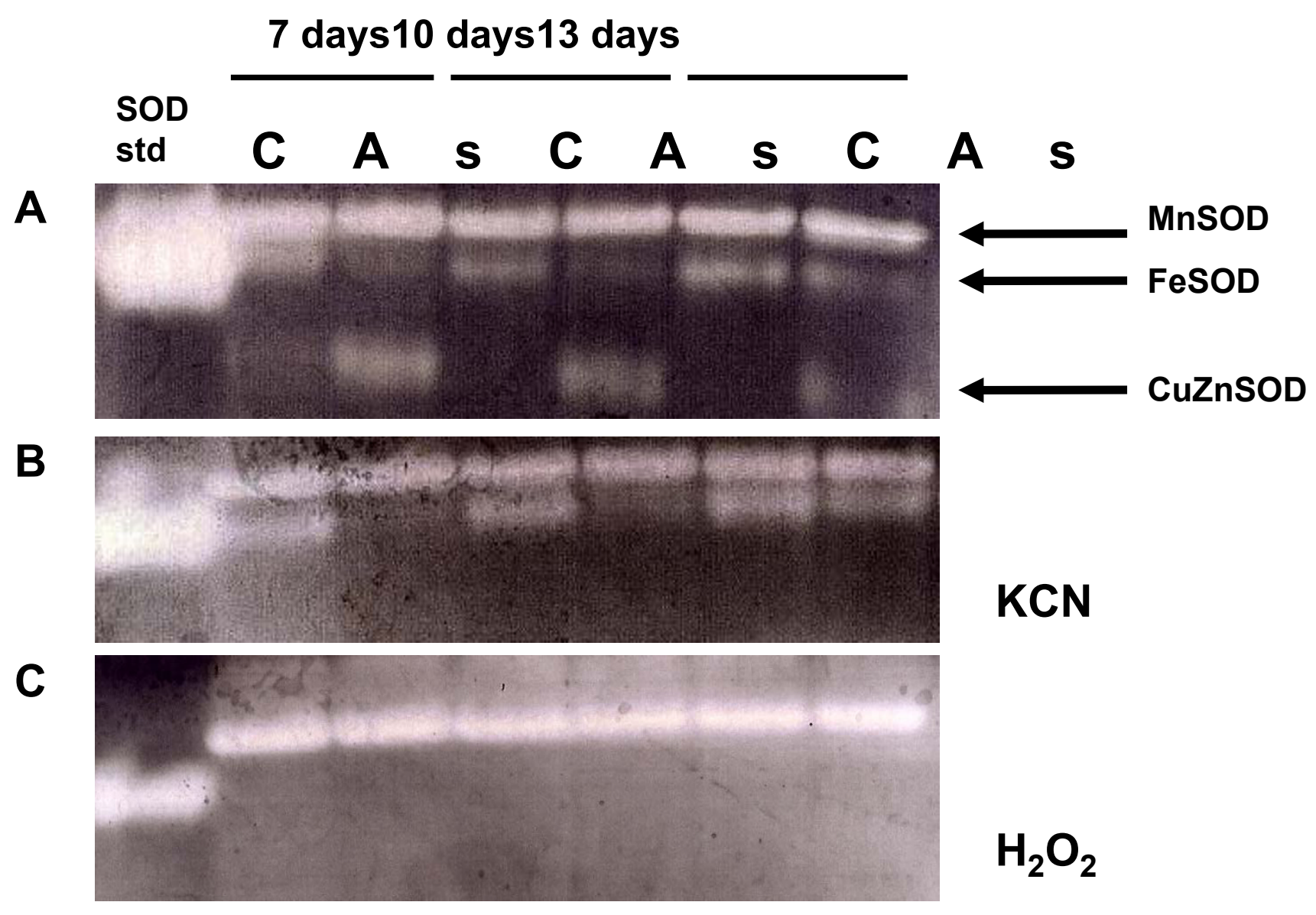

Figure 2

SOD activity in Arabidopsis thaliana 'Col' grown on medium containing $100 \mu \mathrm{M}$ potassium arsenate. A, superoxide dismutase activity without inhibitors, $B$, Gels were preincubated with $\mathrm{KCN}$ (which inhibits CuZn SOD), $\mathrm{C}, \mathrm{H}_{2} \mathrm{O}_{2}$ added as an inhibitor (which inhibits both CuZn SOD and Fe SOD). Lane I, purified bovine SOD positive control. Lane 2, control plants harvested at 7 days, Lane 3, arsenate-treated plants harvested at 7 days. Lane 4, control plants harvested at 10 days, Lane 5, arsenate-treated plants harvested at 10 days. Lane 6, control plants harvested at 13 days, Lane 7, arsenate-treated plants harvested at 13 days.

Plants were harvested from control plates containing no arsenate and treated plates containing $100 \mu \mathrm{M}$ arsenate at seven-, ten-, and thirteen days post-germination. Irrespective of harvest date, CuZnSOD activity was strongly induced by arsenate treatment, whereas FeSOD activity was repressed, and MnSOD showed no change in activity, therefore providing sufficient evidence to confirm our microarray results. Transcription of other antioxidant genes (i.e., peroxidases, glutathione-S transferases, catalase) were indicated by our microarray experiment as affected by arsenate stress, however these genes were not included in our qRT-PCR validation.

\section{Transcription factors}

Our microarray experiment indicated that eight different genes encoding proteins with known transcription factor activity all displayed lower expression levels in As (V)stressed plants (Table 2). One of these transcription factors (at1g12610) encodes a member of the DREB subfamily A-1 of the ERF/AP2 transcription factor family (DDF1). One other AP2-domain-containing transcription factor (at4g34410) that encodes a member of the ERF (ethylene response factor) subfamily B-3 of the ERF/AP2 transcription factor family was also repressed in response to As (V). Two zinc finger ( $\mathrm{C} 2 \mathrm{H} 2$ type) genes (at3g46090, at3g46080) encoded a ZAT7 and a protein similar to ZAT7, respectively. Also exhibiting lower expression in As (V)-treated plants were three members of the WRKY family of transcription factors (at2g38470, at4g23810, at1g80840), WRKY33, WRKY53, and WRKY40, respectively as well as one gene encoding NAC domain containing protein 81 . 


\section{As (V) represses genes involved in phosphate starvation response}

A notable transcriptional trend is that As (V) stress results in repression of some genes involved in the Pi starvation response. Of particular interest, a P-type cyclin (at5g61650) that was affected by As (V)-stress shares significant homology to the PHO80 gene from yeast. We performed qRT-PCR for this gene and found that its expression was actually strongly repressed at both day 3 and day 10 (Table 3; Figure 3). Three genes that were repressed by As (V) in this study have also been reported to be repressed by $\mathrm{Pi}$ starvation [17]. Interestingly, the three highest ranking differentially expressed genes found to be strongly induced by Pi starvation (at1g73010 > at5g20790 > at1g17710, respectively) [18], were also repressed by As (V) in our study. These genes are of particular interest on account of their unknown function. Quantitative RT-PCR confirmed that transcription of these genes was strongly repressed at both 3 day and 10 day time points. Additionally, the qRT-PCR data indicate that these genes were more repressed at day 3 than at day 10 (Table 3; Figure 3). These data also corroborated our microarray experiments, which reflect global expression ratios at 10 days post germination (Table 3 ).

\section{Sulfate assimilation}

The role that thiol groups play in arsenic detoxification has been well characterized, therefore we expected to see

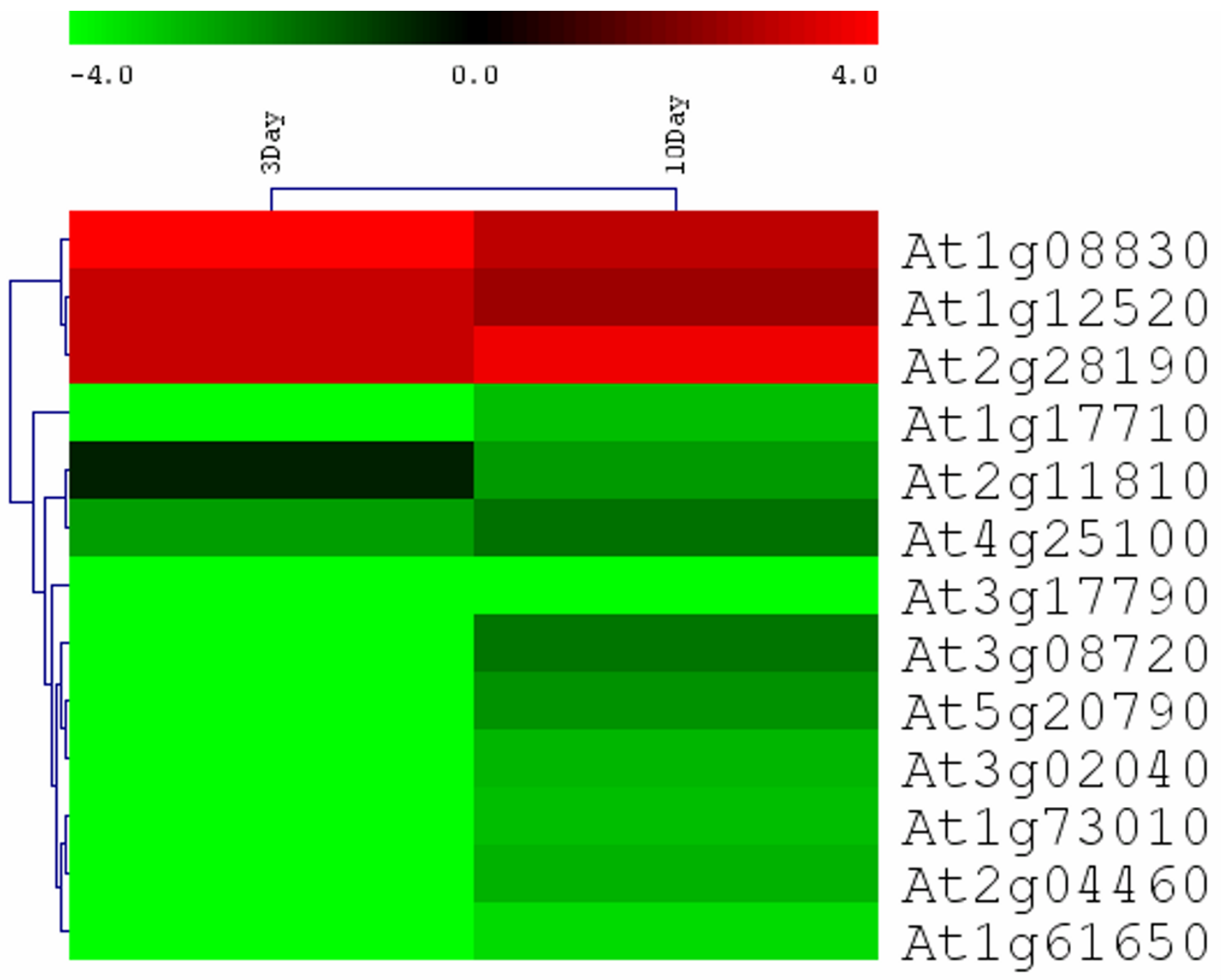

Figure 3

Cluster diagram of $\Delta \Delta \mathrm{Ct}$ values in response to $\mathbf{I 0 0} \mu \mathrm{M}$ arsenate at 3 and $\mathbf{I} 0$ day time points as determined by qRT-PCR. Bright green rectangles represent strongly repressed gene expression (-4-fold and lower), whereas genes strongly induced (4-fold and higher) are shown in bright red. Arabidopsis actin was used as a reference gene to calculate $\Delta \Delta \mathrm{Ct}$. 
induction of genes involved in sulfate assimilation and metabolism in response to arsenic stress. Ferredoxin (at1g10960), a key redox protein found in the chloroplast was As (V)-induced. Expression levels for another gene involved in the sulfate reduction pathway, 5'-adenylylsulfate reductase (APR3) (at4g21190) were also elevated in response to As (V) stress. This enzyme catalyzes the reduction of APS to sulfite using glutathione as an electron donor. Although not involved in sulfate assimilation, the cysteine-rich metal-binding protein, metallothionein (MT) 1A (at1g07600) was also induced. Arabidopsis knockout mutants that were generated for class 1 MTs accumulated significantly less aboveground $\mathrm{As}, \mathrm{Cd}$, and Zn, suggesting that class 1 MTs may play a role in metal and metalloid ion translocation [19].

\section{Genes involved in cell wall assembly, architecture, and growth}

A wide range of genes encoding proteins involved in cell wall activities exhibit altered expression levels in response to As (V) (Table 1; Table 2). Peroxidases, which were indicated by microarray as affected by As (V) stress, are known to strengthen the cell wall in response to biotic stress via formation of lignin, extension cross-links, and dityrosine bonds [20]. Additionally, As (V) affected transcription of numerous xyloglucan endotransglucosylase/hydrolases (XTHs) and glycosyl hydrolase genes (Table 1; Table 2), with the majority of these exhibiting lower expression in the presence of As $(\mathrm{V})$.

\section{Discussion}

Arsenic and oxidative stress

Superoxide dismutases

Increasing evidence from mammalian studies demonstrates that ROS are generated in response to exposure to inorganic forms of arsenic [21-23]. The reduction of arsenic is linked with in vivo and in vitro ROS production in mammalian cells [21], but little is known about the mechanisms by which arsenic-induced ROS generation occurs in plants. It is believed that the reduction of As (V) to As (III), which is well documented in plants, results in the production of ROS $[8,24]$. However, this increase in ROS may also be the result of either depletion of glutathione or inhibition of antioxidant enzymes. Plants have evolved both nonenzymatic antioxidants (i.e., glutathione, ascorbate, and carotenoids), as well as antioxidant enzymes (i.e., superoxide dismutases, catalases, and peroxidases) to manage the balance of ROS in the cell.

SODs represent a first line of defense by converting superoxide radicals to $\mathrm{H}_{2} \mathrm{O}_{2}$, whereas catalases and peroxidases remove $\mathrm{H}_{2} \mathrm{O}_{2}$. Three classes of SODs have been identified according to the active site metal cofactor: FeSOD, MnSOD, and $\mathrm{Cu} / \mathrm{ZnSOD}$. As (V) and As (III) were both shown to induce expression of glutathione S-transferases
(GSTs), catalases, and SODs in Zea mays [24]. An increase in SOD activity was correlated with an increase in As (V) treatment in Holcus lanatus [12]. Higher levels of SOD, catalase, and ascorbate peroxidase were observed in Pteris vittata, an arsenic hyperaccumulator, than in arsenicsensitive fern species Pteris ensiformis and Nephrolepsis exaltata [25]. These researchers concluded that arsenicinduced increases in antioxidant enzymes levels may represent a secondary defensive mechanism against oxidative stress in Pteris vitatta and correspond with its arsenic accumulation and lack of toxicity symptoms. It was shown that Pteris vittata SOD, catalase, and peroxidase levels rose sharply in response to low levels of As (V), but leveled off at As (V) levels $>20 \mathrm{mg} \mathrm{kg}^{-1}$, which was consistent with changes in biomass in the arsenic hyperaccumulator [26].

Although the strong induction of SODs in response to As (V) stress was not surprising, the dramatically lower levels of FeSODs were unexpected. We suggest the involvement of an NAC domain-containing transcription factor to explain the observed decrease in FeSOD transcription based on our microarray results (Table 2). One group recently generated transgenic plants to overexpress three different Arabidopsis NAC transcription factors and identified NAC-dependent genes using microarrays [27]. Not only was at4g25100 (FeSOD) expression found to be NAC-dependent, but transcription of other genes we have observed to be repressed by As (V) stress also appear to be dependent on NAC-domain containing transcription factors. We continue this discussion more thoroughly in the following section on transcription factors.

\section{Peroxidases}

Peroxidases are functionally diverse and participate in two major cycles: the hydroxylic cycle where peroxidases regulate $\mathrm{H}_{2} \mathrm{O}_{2}$ levels and release $\mathrm{ROS}(\cdot \mathrm{OH}, \mathrm{HOO} \cdot)$ and the peroxidative cycle where various substrates (e.g. phenolic compounds) are oxidized or polymerized. Their involvement in a broad range of physiological processes allows peroxidase expression in all plant organs from germination to early senescence, however they are predominantly expressed in the roots [20]. It is not surprising that peroxidases seem to be affected by arsenate stress (Table 1; Table 2), especially in consideration of the elevated SOD activity, which produces $\mathrm{H}_{2} \mathrm{O}_{2}$ as a product of superoxide radical dismutation.

\section{Transcription factors}

Our microarray data corroborate those of Tran et al. [27], suggesting the involvement of a different NAC domaincontaining transcription factor (at5g08790) in expression of FeSOD, as well as several other genes known to exhibit NAC-dependent expression. NAC proteins comprises a large gene family (> 100 members in Arabidopsis) of plant-specific transcription factors that have roles in wide- 
ranging processes such as development, defense, and abiotic stress response [28]. Microarray experiments were carried out on NAC-overexpression Arabidopsis mutants to discover genes exhibiting dependence on NAC transcription factors for transcription [27]. We speculate that repression of NAC81 (at5g08790) in As (V)-stressed Arabidopsis may be responsible for the observed repression of FeSOD (at4g25100), ferritin 1 (FER 1) (at5g01600), XTH15 (at4g14130), XTH24 (at4g30270), erd1 ATPdependent Clp protease ATP-binding subunit (at5g51070), and a branched-chain amino acid amino transferase 2 (at $1 \mathrm{~g} 10070)$, as these genes were reported as exhibiting NAC-dependent expression [27].

\section{As (V) stress represses genes induced by $\mathrm{Pi}$ deprivation}

Although phosphate is undoubtedly one of the most biologically important nutrients, its availability in soils is quite low. Therefore, plants have evolved mechanisms to maximize Pi accessibility/availability, such as increased root hair growth, lateral root branching, and induction of phosphate transporters and phosphatases [29]. Certain phosphate starvation-induced genes have evolved to release phosphate from plasma membranes by hydrolyzing phospholipids under conditions of low Pi availability, as phospholipids comprise a major Pi pool in planta [30]. Conversion from phospholipids to galactolipids is one such strategy and can result from the activity of monogalactosyldiacylglycerol (MGDG) synthase or digalactosyl diacylglycerol (DGDG) synthase [31]. Arabidopsis plants expressing MGD2 and MGD3 promoter-GUS fusion constructs showed that under Pi starvation, MGD3::GUS was expressed in apices of serrated edges (hydathodes) and in the lateral root branch [31]. Through investigation of Arabidopsis MGDG synthase gene expression under Pi starvation, these authors showed that global changes in plant membranes under Pi deprivation are tightly regulated by $\mathrm{Pi}$ signaling and that signal transduction through a Pisensing mechanism is responsible for regulating MGDG synthase gene expression [31]. We report here that the expression of MGD3 (at2g11810) is lower in As (V)treated Arabidopsis at 3 days and 10 days (Table 3; Figure $3)$. Therefore, it is conceivable that our observations may either reflect a Pi/As (V) sensing mechanism or simply the lower number of lateral roots in As (V)-stressed plants (Figure 1). SENESCENCE RELATED GENE 3 (SRG3; at3g02040), a glycerophosphoryl diester phosphordiesterase, is believed to participate in processes similar to those of the MGDG synthase genes [32]SRG3 had lower transcript abundance in As (V)-treated plants in our microarray study (along with other senescence-associated proteins) (Table 2), as well as, in 3 day and 10 day As (V)treated plants (Table 3; Figure 3). A type 5 acid phosphatase (ACP5; at3g17790) was also repressed in our As (V)-treated plants as indicated by microarray (Table 2) and was strongly repressed in our qRT-PCR validation experiments at both 3 day and 10 day time points (Table 3; Figure 3). In Arabidopsis, ACP5 has been shown to be induced by $\mathrm{H}_{2} \mathrm{O}_{2}$, but not by paraquat or salicylic acid and is thought to be involved in both phosphate mobilization and in the metabolism of reactive oxygen species [33]. In contrast, ACP5 was strongly repressed by As (V) despite elevated SOD levels, which generate $\mathrm{H}_{2} \mathrm{O}_{2}$. Therefore, further study is required to determine the specific cause of As (V)-mediated ACP5 repression.

Recent investigations into the genome-scale transcriptional changes to phosphate deprivation in Arabidopsis have elucidated a broad range of genes involved in phosphate metabolism $[17,18]$. Our microarray data suggested that many genes repressed by As $(\mathrm{V})$ stress have been reported by others $[17,18]$ to be induced in response to Pi deprivation in Arabidopsis thaliana. Because As (V) behaves as a phosphate analog, it is likely that this observation can be explained by a saturation effect of the phosphate ana$\log$, As (V), thereby misleading metabolic and regulatory perception of the toxic metalloid as an abundant supply of Pi. However, arsenate likely disrupts critical biological processes that involve reversible phosphorylation, as well as pathways for phosphate signaling, but even under arsenate stress, Arabidopsis accumulates much higher concentrations of As in the root than is translocated to the shoot. In another study, when wild-type (Columbia ecotype) Arabidopsis plants were grown on $100 \mu \mathrm{M}$ sodium arsenate for 3 weeks, low concentrations of arsenic were accumulated in the shoot, whereas high concentrations of arsenic were observed in roots [34]. However, when the arsenate reductase homolog (ACR2) was silenced, arsenate was translocated to the shoot at concentrations that classified as hyperaccumulation [34]. Nevertheless, the signaling mechanisms by which plants distinguish between As (V) and phosphate are unknown and other mechanisms of As detoxification and storage besides the well documented phytochelatin response [9-12] may exist.

In order to confirm the observation that As (V) stress represses genes involved in phosphate starvation/acquisition, we performed qRT-PCR on some of the more interesting candidates (Table 3; Figure 3). We are particularly interested in elucidating pathways involved in As (V) signaling in plants. The P-type cyclin (at5g61650) that was affected by As (V) (Table 3; Figure 3) shares significant homology to the PHO80 gene from yeast. Cyclins bind and activate cyclin-dependent kinases, which play key roles in cell division via phosphorylation of critical substrates, such as the retinoblastoma protein, transcription factors, nuclear laminar proteins, and histones [35]. Interestingly, it was demonstrated that expression of this cyclin from Arabidopsis restored the phosphate signaling path- 
way in a PHO80-deficient yeast mutant, suggesting a putative key Pi signaling role [36].

Protein kinases play crucial roles in signal transduction pathways in all eukaryotes [37]. At3g08720 (ATPK19) is one of two nearly identical kinase genes in Arabidopsis that encode for proteins that share high sequence homology with the mammalian $40 \mathrm{~S}$ ribosomal protein kinases S6K1 and S6K2 [38]. ATPK19 was demonstrated to be the functional plant homolog of mammalian p70s6k when ectopic expression of this gene specifically phosphorylated ribosomal protein S6 derived from either plant or animal [39]. ATPK19 has recently been implicated as a crucial nodal point in a network evolved for integrating stress signals with plant growth regulation [40]. Lower expression levels observed for ATPK19 in As (V)-treated plants, which was most severe at day 3 (Table 3; Figure 3), lends us to conclude that As (V) stress may suppress plant growth through the downregulation of this growth-regulating kinase, possibly as a result of the chemical similarity between As (V) and phosphate. Alternatively, the downregulation of ATPK19 may result from the more general stress responses imposed by the toxic metalloid (e.g. oxidative stress, sulfhydryl group binding, etc.).

Our results are in agreement with the recently proposed ideas of Catarecha et al. [41] who studied an Arabidopsis mutant that displayed enhanced arsenic accumulation. These authors identified a Pi transporter (PHT1;1) mutant with a decreased rate of As (V) uptake and increased As (V) accumulation. By comparing gene expression of the mutant with wild-type plants, it was shown that in Arabidopsis, As (V) rapidly repressed genes involved in the Pi starvation response and induced the expression of other As (V)-responsive genes [41]. Interestingly, the repression of Pi starvation genes was shown to be specific for As (V), whereas the As (V)-induced genes were also induced by As (III). A model resulted that suggests arsenic acts via two separate signaling pathways [41]. Because of the chemical similarity of As (V) and $\mathrm{Pi}$, As (V) fools the Pi sensor, thus initiating the repression of the $\mathrm{Pi}$ starvation response. Although our microarray experiments did not detect differential expression of any high-affinity Pi transporter, which may be due to differences in experimental approach, Catarecha et al. [41] illustrated the high sensitivity of the Pi transporter, PHT1;1, to As (V) and suggested that plants have evolved an As (V) sensing system whereby As (V) and Pi signaling pathways oppose each other to protect the plant from arsenic toxicity. Based on our results, it is conceivable that the P-type cyclin (at5g61650) and ATPK19 (at3g08720) may be involved in As (V) sensing, but further study is required to confirm this finding.
Our comparison of As (V)-repressed genes that have also been shown to be induced by $\mathrm{Pi}$ deprivation elucidate some promising candidates for future studies. For example, we are particularly interested in genes with unknown function that are strongly induced in both roots and leaves by $\mathrm{Pi}$ starvation (i.e. at1g73010; at1g17710; at2g04460; at5g20790; [17], supplemental data; [18]). Both at1g73010 and at1g17710 are described as phosphoric monoester hydrolases (see Availability and requirements section for URL), but to our knowledge, these have not been studied in this regard. Most recently, a study described gene networks for the Arabidopsis transcriptome based on the graphical Gaussian model of global-scale transcriptional studies [32]. In a constructed subnetwork of genes involved in phosphate starvation, SRG3, at1g73010, at3g17790 (ACP5), at2g11810, and at5g20790 were all closely linked, suggesting their critical roles in phosphate metabolism in Arabidopsis [32]. Based on their strong induction in response to $\mathrm{Pi}$ starvation $[17,18]$, it is reasonable to conceive that at 1 g73010 and at1g17710 have evolved as Pi scavengers for increasing Pi availability. We have confirmed the downregulation of these genes in response to As (V) at both 3 and 10 day time points (Table 3; Figure 3). In this study, at2g04460 transcript levels were strongly repressed at 3 and 10 day time points, whereas at5g20790 was repressed at day 3 and day 10 (Table 3; Figure 3). Interestingly, at2g04460 encodes for a putative retroelement pol polyprotein that has been reported as highly expressed in salt overly sensitive (sos) Arabidopsis mutants [42]. Because the function of these two Pi starvation-induced genes is unknown, these putative gene candidates may provide opportunities for gaining insight into As (V)/Pi dynamics in Arabidopsis thaliana.

The data presented here have led to the development of new hypotheses for future research. The potential antagonistic effects of various arsenate and Pi concentrations on the expression of the aforementioned genes in Arabidopsis are poorly understood. Additionally, the efficiency of arsenate reduction and subsequent detoxification via phytochelatins or glutathione is poorly understood. Under conditions of arsenate stress (i.e., $100 \mu \mathrm{M}$ ), perhaps the cellular concentrations of arsenate surpass those that may be efficiently reduced by glutathione or arsenate reductase, thus allowing free arsenate to interfere with biological reactions that involve phosphate. Additionally, the selected arsenate concentration to employ in this study could have resulted in free arsenite after reduction in vivo that would likely have deleterious consequences. Therefore, it is reasonable to conceive that the observed transcriptional responses, as well as the impaired phenotype seen in this study, may be reflective of either arsenate, arsenite, or both. 


\section{Conclusion}

Our data show that in Arabidopsis, Cu/Zn SODs are strongly induced in response to As (V) stress, while Fe SOD expression is repressed. We also demonstrate that As (V) stress results in the repression of genes involved in phosphate acquisition, redistribution, and phosphorylation, which supports a recent study [41] that suggests As (V) and Pi signaling pathways act in opposition to protect plant health. Although this study identifies some interesting targets for exploring As (V) metabolism, further studies using Arabidopsis mutants with altered expression of these genes are necessary to elucidate their biological significance, as well as to clarify new pathways involved in arsenic signaling in plants.

\section{Methods}

Plants and growth conditions

Seeds of Arabidopsis thaliana ecotype Columbia plants were surface sterilized and plated on agar-solidified MS culture medium supplemented with B5 vitamins, 10\% sucrose, 2\% Gelrite ${ }^{\circledast}$, pH 5.8. Phosphate is supplied as $1.25 \mathrm{mM} \mathrm{KH}_{2} \mathrm{PO}_{4}$ in the culture medium. Arsenic-treated plates were supplemented with $100 \mu \mathrm{M}$ potassium arsenate (Sigma) according to a previously determined sublethal growth response curve. Plates were cold stratified at $4{ }^{\circ} \mathrm{C}$ for $24 \mathrm{hrs}$ and then placed in a growth chamber at $25^{\circ} \mathrm{C}$ under a $16 \mathrm{hr}$ photoperiod. At each time point $(3 \mathrm{~d}$, $10 \mathrm{~d}), 2 \mathrm{~g}$ of whole plant material (shoots + roots) was harvested from each plate, frozen in liquid nitrogen, and subjected to RNA isolation using Trizol ${ }^{\circledR}$ reagent (Invitrogen, Carlsbad, CA) according to manufacturer's protocol. A total of three biological replicates were assayed (3 control, 3 treated) where each pooled 2 g sample represented a single biological replicate.

\section{Microarray experiments and aRNA labeling}

Total RNA from six biological replicates were purified using RNeasy MiniElute columns (Qiagen, Valencia, CA). A total of $1.25 \mu \mathrm{g}$ of purified total RNA was subjected to Aminoallyl Message Amp II kit (Ambion, Austin, TX) first strand cDNA synthesis, second strand synthesis, and in vitro transcription for amplified RNA (aRNA) synthesis. aRNA was purified according to manufacturers protocol (Ambion, Austin, TX) and quantified using a Nanodrop spectrophotometer. Two $4 \mu \mathrm{g}$ samples of aRNA were labeled with Cy3 and Cy5 monoreactive dyes (Amersham Pharmacia, Pittsburgh, PA) in order to conduct a dye swap technical replicate for each biological replicate. Each aRNA sample was brought to dryness in a Speedvac and dissolved in $5 \mu \mathrm{L}$ of $0.2 \mathrm{M} \mathrm{NaHCO}_{3}$ buffer. Five microliters of Cy3 or Cy5 (in DMSO) was added to each sample and incubated for 2 hrs in the dark at RT. Labeled aRNA was purified according to kit instructions (Ambion, Austin, TX) and quantified using the Nanodrop spectrophotometer. One-hundred pmol Cy3- and Cy5-labeled aRNA targets were denatured by incubating at $65^{\circ} \mathrm{C}$ for $5 \mathrm{~min}$ and added to a hybridization mix containing $9 \mu \mathrm{l} 20 \times$ SSC, $5.4 \mu$ l Liquid Block (Amersham Pharmacia, Pittsburgh, PA), and $3.6 \mu \mathrm{l}$ 2\% SDS for a $90 \mu \mathrm{l}$ total volume.

\section{Hybridization and data analysis}

Microarrays comprised of 70-mer oligonucleotides obtained from the University of Arizona (see Availability and requirements section for URL) were immobilized by rehydrating the slide over a $50^{\circ} \mathrm{C}$ waterbath for $10 \mathrm{~s}$ and snap drying on a $65^{\circ} \mathrm{C}$ heating block for $5 \mathrm{~s}$ for a total of four times. Slides were UV-crosslinked at $180 \mathrm{~mJ}$ in a UV cross-linker (Stratagene, La Jolla, CA). The slides were then washed in 1\% SDS, dipped in 100\% EtOH five times followed by 3 min shaking. Slides were spun dry at 1000 rpm for 2 minutes and immediately placed in a lightproof box. The $90 \mu \mathrm{l}$ hybridization mix was pipetted onto a microarray slide underneath a lifterslip (Lifterslip, Portsmouth, NH) and placed in a hybridization chamber (Corning, Corning, NY) overnight at $55^{\circ} \mathrm{C}$. After hybridization, slides were washed in $2 \times$ SSC, $0.5 \%$ SDS for 5 minutes at $55^{\circ} \mathrm{C}, 0.5 \times \mathrm{SSC}$ for 5 minutes at room temperature, and $0.05 \times$ SSC for 5 minutes at room temperature. Slides were then spun dry at $1000 \mathrm{rpm}$ in a Sorvall centrifuge and scanned with a GenePix 4000B scanner (Axon Instruments, Inc., Union City, CA). The intensity variation was removed by fitting a loess regression using SAS 9.1 (SAS, Cary, NC). Data were log-2 transformed and statistically analyzed using rank product statistics as described by [43] to identify differentially expressed genes. Bioconductor Rank Prod package was used to perform the rank product analysis $[44,45]$. Significantly different genes reported in this study exhibited $P<0.001$, as designated by the rank product analysis. The false discovery rate (FDR) [46] value obtained was based on 10,000 random permutations. Since 10,000 random permutations was very computer intensive, 1000 random permutations were performed 10 different times each time starting with a different random seed number and the average FDR value calculated was used for further analysis. The genes that had FDR values less than or equal to 0.01 were considered as differentially expressed. Data for all microarray experiments were submitted to the NCBI GEO microarray database and can be viewed under the accession GSE10425.

\section{Microarray Data Quality Control}

Global gene expression profiling comparing arsenatetreated Arabidopsis plants with control was carried out to better understand the mechanisms of plant response to arsenate stress and to identify genes involved in arsenic metabolism. For microarray data quality control, we examined both dye dependent effects and distribution of the ratio after normalization. We have included an additional file that illustrates the quality of microarray experiments, as well as the overall gene expression pattern [see 
Additional file 2]. Additional file 2a shows the normalized $\mathrm{M}$ vs. A plot, which was generated as a scatter plot of $\log$ intensity ratios $M=\log _{2}(R / G)$ versus average log intensities $A=\log _{2}\left(R^{*} G\right) / 2$, where $R$ and $G$ represent the fluorescence intensities in the $\mathrm{Cy} 3$ and $\mathrm{Cy} 5$ channels, respectively [47]. As shown by the figure, Loess normalization effectively removed dye dependent effects in the microarray and rendered evenly distributed ratios across all signal intensities. The histogram suggests a normal distribution of the logarithm 2-based transformed ratio [see Additional file 2b]. Overall, the microarray experiments generated high quality data without significant dyedependent effects and skewness of ratio distribution.

\section{Gene ontology analysis}

Gene ontology annotations were translated from microarray data using the GO annotations bioinformatics tool available at The Arabidopsis Information Resource Web site http://www.arabidopsis.org/tools/ where results were based on molecular function.

\section{RT-PCR amplification}

Total RNA was extracted from Arabidopsis thaliana ecotype Columbia grown for ten days as described for the microarray experiment. Five micrograms of total RNA was reverse-transcribed with oligo $(\mathrm{dT})_{20}$ primers using the Superscript III first-strand cDNA synthesis kit (Invitrogen, Carlsbad, CA). RT PCR was performed using the ABI 7000 Sequence Detection System (Applied Biosystems, Foster City, CA). PCR was performed in a $15 \mu \mathrm{l}$ reaction volume containing Power Sybr ${ }^{\circledast}$ PCR mix (Applied Biosystems, Foster City, CA) and gene-specific primers were designed with PrimerExpress software. Actin was used as the reference gene, and the primer sequences for Arabidopsis actin gene were AGTGGTCGTACAACCGGTATTGT (F) and GAGGAAGAGCATTCCCCTCGTA (R). After the RT PCR experiment, $\mathrm{Ct}$ number was extracted for both reference gene and target gene with auto baseline and manual threshold.

\section{Cluster Analysis}

The cluster analysis was conducted with MultiExperiment viewer Version 4.0 (TIGR, Rockville, MD) with logarithm 2 transformed ratio of treated vs. control samples from real-time PCR. The complete linkage hierarchical cluster was used to cluster the genes only. The color scheme is as shown in the figure, with repressed genes shown as green and red color indicating induced genes.

\section{SOD activity assay}

Total soluble protein was extracted from whole Arabidopsis plants (root + shoot) grown on plates as described above that were harvested at each respective time point. Total soluble protein was quantified by the method of
Bradford [48] using BSA as a standard and $50 \mu \mathrm{g}$ samples were loaded. Bovine SOD (Sigma) was used in each gel to serve as a positive control for SOD activity. Following electrophoretic separation on a $10 \%$ non-denaturing polyacrylamide gel, SOD activity was determined as described by Beauchamp and Fridovich (1971) and modified by Azevedo et al. [49]. The gels were rinsed with DDI water and incubated in the dark for $30 \mathrm{~min}$ at room temperature in a reaction mixture containing $50 \mathrm{mM}$ potassium phosphate buffer (pH 7.8), $1 \mathrm{mM}$ EDTA, $0.05 \mathrm{mM}$ riboflavin, $0.1 \mathrm{mM}$ nitroblue tetrazolium and $0.3 \%(\mathrm{v} / \mathrm{v})$ TEMED. Following incubation, gels were rinsed with DDI water and illuminated in water until SOD bands were visible. The gels were then immersed in a $6 \%(\mathrm{v} / \mathrm{v})$ acetic acid solution to stop the reaction. To confirm specificity of $\mathrm{Cu} / \mathrm{Zn}$-SOD activity, $\mathrm{H}_{2} \mathrm{O}_{2}$ and $\mathrm{KCN}$ were used as inhibitors as described by Azevedo et al. [49] and modified by Vitoria et al. [50]. Mn-SOD is resistant to both inhibitors, $\mathrm{Fe}-\mathrm{SOD}$ is resistant to KCN and inhibited by $\mathrm{H}_{2} \mathrm{O}_{2}$, and $\mathrm{Cu} / \mathrm{Zn}$-SOD is inhibited by both inhibitors, thus allowing classification of SOD activity. Prior to SOD staining, gels containing lanes in triplicate were cut into three parts; one gel was treated as described above, the second and third parts were incubated for $20 \mathrm{~min}$ in 100 $\mathrm{mM}$ potassium phosphate buffer $(\mathrm{pH} 7.8)$ containing either $2 \mathrm{mM} \mathrm{KCN}$ or $5 \mathrm{mM} \mathrm{H}_{2} \mathrm{O}_{2}$, respectively. Following incubation, gels were rinsed with DDI water and then stained for SOD activity.

\section{Availability and requirements}

US Environmental Protection Agency: http:// www.atsdr.cdc.gov/cercla/05list.html

University of Arizona: http://ag.arizona.edu/microarray/

The Arabidopsis Information Resource: http://www.ara bidopsis.org/tools/

\section{Authors' contributions}

Jason Abercrombie conceived of the study, its experimental design, and overall data interpretation and drafting of the manuscript. Matt Halfhill contributed to the experimental design, data interpretation, and technical assistance. Priya Ranjan, Murali Rao, and Arnold Saxton all conducted the non-parametric statistical analyses of the microarray data and reprogrammed the RankProd package to carry out 10,000 random permutations of the data and provided intellectual input for the statistical interpretation of the data. C. Neal Stewart, Jr. supervised organization of the manuscript, provided critical analyses of the data, and gave final approval of its readiness for submission. All authors read and approved the final manuscript. 


\section{Additional material}

\section{Additional file 1}

Functional characterization of differentially expressed A. thaliana genes in response to As (V) stress.

Click here for file

[http://www.biomedcentral.com/content/supplementary/14712229-8-87-S1.pdf]

\section{Additional file 2}

Microarray quality control for chips used in this study.

Click here for file

[http://www.biomedcentral.com/content/supplementary/14712229-8-87-S2.pdf]

\section{Additional file 3}

Complete microarray dataset for genes induced by As (V).

Click here for file

[http://www.biomedcentral.com/content/supplementary/14712229-8-87-S3.xls]

\section{Additional file 4}

Complete microarray dataset for genes repressed by As (V).

Click here for file

[http://www.biomedcentral.com/content/supplementary/14712229-8-87-S4.xls]

\section{Acknowledgements}

We appreciate our collaborators at Edenspace Systems Corporation for their valuable cooperation, especially, Mark Elless, David Lee, and Bruce Ferguson. We thank Laura Abercrombie and Reggie Millwood for technical assistance. Funding was provided by NIH and NSF grants as well as the Tennessee Agriculture Experiment Station and the Ivan Racheff Endowment. We would also like to thank the BMC Plant Biology editors and 4 anonymous reviewers for their thorough reviews and constructive criticism of this manuscript.

\section{References}

I. Moore L, Fleishcher M, Woolson E: Distribution of arsenic in the Environment. In Medical and Biologic Effects of Environmental Pollut ants: Arsenic Edited by: Grossblatt N. Washington, D.C.: National Academy of Sciences; 1977:16-26.

2. International Agency for Research on Cancer: Monograph of the evaluation of carcinogenic risk to humans - Overall evaluation of carcinogenicity. An update of IARC monographs I to 42 . Lyon

3. Chakraborti D, Mukherjee SC, Pati S, Sengupta MK, Rahman MM, Chowdhury UK, Lodh D, Chanda CR, Chakraborti AK, Basu GK Arsenic groundwater contamination in Middle Ganga Plain, Bihar, India: a future danger? Environ Health Perspect 2003, I I I:| |94-1201.

4. Mukhopadhyay R, Rosen B, Phung L, Silver S: Microbial arsenic: from geocycles to genes and enzymes. FEMS Microbiol Rev 2002, 26:3| |-325

5. National Research Council: Arsenic in drinking water. National Academy Press: Washington, D.C; 1999.

6. Quaghebeur M, Rengel Z: The distribution of arsenate and arsenite in shoots and roots of Holcus lanatus is influenced by arsenic tolerance and arsenate and phosphate supply. Plant Phys 2003, I32:1600-1609.

7. Ullrich-Eberius C, Sanz A, Novacky A: Evaluation of arsenate- and vanadate-associated changes of electrical membrane poten- tial and phosphate transport in Lemna gibba-GI. J Exp Bot 1989, 40:119-128.

8. Meharg A, Hartley-Whitaker J: Arsenic uptake and metabolism in arsenic-resistant and non-resistant plant species. New Phytologist 2002, I 54:29-43.

9. Pickerling I, Prince R, George M, Smith R, George G, Salt D: Reduction and coordination of arsenic in Indian mustard. Plant Phys 2000, I22:1171-I177.

10. Grill E, Loffler S, Winnaker E, Zenk M: Phytochelatins, the heavymetal-binding peptides of plants, are synthesized from glutathione by a specific $\gamma$-glutamylcysteine dipeptidyl transpeptidase (phytochelatin synthase). Proc Natl Acad Sci USA 1989, 86:6838-6842

II. Schmoger M, Oven M, Grill E: Detoxification of arsenic by phytochelatins in plants. Plant Phys 2000, I 22:793-80I.

12. Hartley-Whitaker J, Ainsworth G, Vooijs R, Ten Bookum W, Schat H, Meharg AA: Phytochelatins are involved in differential arsenate tolerance in Holcus lanatus. Plant Physiol 200I, I 26:299-306.

13. Kertulis-Tartar GM, Ma LQ, Tu C, Chirenje T: Phytoremediation of an arsenic-contaminated site using Pteris vittata L.: a twoyear study. Int J Phytoremediation 2006, 8:3 I I-322.

14. Tu C, Ma LQ, Bondada B: Arsenic accumulation in the hyperaccumulator Chinese brake and its utilization potential for phytoremediation. J Environ Qual 2002, 3 I: |67|-1675.

15. Wei CY, Chen TB: Arsenic accumulation by two brake ferns growing on an arsenic mine and their potential in phytoremediation. Chemosphere 2006, 63:1048-1053.

16. Beauchamp C, Fridovich I: Superoxide dismutase: Improved assays and an assay applicable to acrylamide gels. Anal Chem I97I, 44:276-287.

17. Misson J, Raghothama KG, Jain A, Jouhet J, Block MA, Bligny R, Ortet P, Creff A, Somerville S, Rolland N, Doumas P, Nacry P, HerrerraEstrella L, Nussaume L, Thibaud MC: A genome-wide transcriptional analysis using Arabidopsis thaliana Affymetrix gene chips determined plant responses to phosphate deprivation. Proc Natl Acad Sci USA 2005, I 02: I I934-II939.

18. Morcuende R, Bari R, Gibon Y, Zheng W, Pant BD, Blasing O, et al.: Genome-wide reprogramming of metabolism and regulatory networks of Arabidopsis in response to phosphorus. Plant Cell Environ 2007, 30:85-II2.

19. Zimeri AM, Dhankher OP, McCaig B, Meagher RB: The plant MT I metallothioneins are stabilized by binding cadmiums and are required for cadmium tolerance and accumulation. Plant $\mathrm{Mol}$ Biol 2005, 58:839-855.

20. Passardi F, Cosio C, Penel C, Dunand C: Peroxidases have more functions than a Swiss army knife. Plant Cell Rep 2005, 24:255-265

21. Hei TK, Liu SX, Waldren C: Mutagenicity of arsenic in mammalian cells: role of reactive oxygen species. Proc Natl Acad Sci USA 1998, 95:8103-8107.

22. Liu SX, Athar M, Lippai I, Waldren C, Hei TK: Induction of oxyradicals by arsenic: implication for mechanism of genotoxicity. Proc Natl Acad Sci USA 200 I, 98: I 643-1648.

23. Qian $Y$, Castranova $V$, Shi $X$ : New perspectives in arsenicinduced cell signal transduction. J Inorg Biochem 2003 , 96:27I-278.

24. Mylona PV, Polidoros AN, Scandalios JG: Modulation of antioxidant responses by arsenic in maize. Free Radic Biol Med 1998 , 25:576-585

25. Srivastava M, Ma LQ, Singh N, Singh S: Antioxidant responses of hyper-accumulator and sensitive fern species to arsenic. J Exp Bot 2005, 56(4 I 5): I 335-1 342.

26. Cao X, Ma LQ, Tu C: Antioxidant responses to arsenic in the arsenic-hyperaccumulator Chinese brake fern (Pteris vittata L.). Env Poll 2004, I 28:3 I 7-325.

27. Tran LS, Nakashima K, Sakuma Y, Simpson SD, Fujita Y, Maruyama K, Fujita M, Seki M, Shinozaki K, Yamaguchi-Shinozaki K: Isolation and functional analysis of Arabidopsis stress-inducible NAC transcription factors that bind to a drought-responsive cis-element in the early responsive to dehydration stress I promoter. Plant Cell 2004, I 6:248I-2498.

28. Olsen AN, Ernst HA, Leggio LL, Skriver K: NAC transcription factors: structurally distinct, functionally diverse. Trends Plant Sci 2005, 10:79-87.

29. Abel K, Anderson RA, Shears SB: Phosphatidylinositol and inositol phosphate metabolism. J Cell Sci 200 I, I I 4:2207-2208. 
30. Dormann P, Benning C: Galactolipids rule in seed plants. Trends Plant Sci 2002, 7: I I2-II8.

31. Kobayashi K, Masuda T, Takamiya K, Ohta H: Membrane lipid alteration during phosphate starvation is regulated by phosphate signaling and auxin/cytokinin cross-talk. Plant J 2006, 47:238-248.

32. Ma S, Gong Q, Bohnert HJ: An Arabidopsis gene network based on the graphical Gaussian model. Genome Res 2007, I 7:1614-1625.

33. del Pozo JC, Allona I, Rubio V, Leyva A, de la Pena A, Aragoncillo C, Paz-Ares ]: A type 5 acid phosphatase gene from Arabidopsis thaliana is induced by phosphate starvation and by some other types of phosphate mobilising/oxidative stress conditions. Plant J 1999, 19:579-589.

34. Dhankher OP, Rosen BP, McKinney EC, Meagher RB: Hyperaccumulation of arsenic in the shoots of Arabidopsis silenced for arsenate reductase (ACR2). Proc Natl Acad Sci USA 2006, 103:54|3-54|8.

35. Morgan DO: Cyclin-dependent kinases: engines, clocks, and microprocessors. Annu Rev Cell Dev Biol 1997, 13:26I-29I.

36. Torres Acosta JA, de Almeida Engler J, Raes J, Magyar Z, De Groodt R, Inze D, De Veylder L: Molecular characterization of Arabidopsis PHO80-like proteins, a novel class of CDKA; I-interacting cyclins. Cell Mol Life Sci 2004, 61:| 1485-1497.

37. Hunter T: Protein kinases and phosphatases: the yin and yang of protein phosphorylation and signaling. Cell 1995, 80:225-236.

38. Volarevic S, Thomas G: Role of $\mathbf{S 6}$ phosphorylation and $\mathbf{S 6}$ kinase in cell growth. Prog Nucleic Acid Res Mol Biol 200I, 65:10I- 127.

39. Turck F, Kozma SC, Thomas G, Nagy F: A heat-sensitive Arabidopsis thaliana kinase substitutes for human $\mathbf{p 7 0}^{\text {s6k }}$ function in vivo. Mol Cell Biol 1998, 18:2038-2044.

40. Mahfouz MM, Kim S, Delauney AJ, Verma DP: Arabidopsis TARGET OF RAPAMYCIN interacts with RAPTOR, which regulates the activity of S6 kinase in response to osmotic stress signals. Plant Cell 2006, 1 8:477-490.

4I. Catarecha P, Segura MD, Franco-Zorrilla JM, Garcia-Ponce B, Lanza M, Solano R, Paz-Ares J, Leyva A: A Mutant of the arabidopsis phosphate transporter PHTI;I displays enhanced arsenic accumulation. Plant Cell 2007, 19:1 I23-I I33.

42. Gong Z, Koiwa H, Cushman MA, Ray A, Bufford D, Kore-eda S, Matsumoto TK, Zhu J, Cushman JC, Bressan RA, Hasegawa PM: Genes that are uniquely stress regulated in salt overly sensitive (sos) mutants. Plant Physiol 200I, I 26:363-375.

43. Breitling R, Armengaud P, Amtmann A, Herzyk P: Rank products: a simple, yet powerful, new method to detect differentially regulated genes in replicated microarray experiments. FEBS Lett 2004, 573:83-92.

44. Hong F, Breitling R, McEntee CW, Wittner BS, Nemhauser JL, Chory J: RankProd: a bioconductor package for detecting differentially expressed genes in meta-analysis. Bioinformatics 2006, 22:2825-2827.

45. Gentleman RC, Carey VJ, Bates DM, Bolstad B, Dettling M, Dudoit S, Ellis B, Gautier L, Ge Y, Gentry J, Hornik K, Hothorn T, Huber W, lacus S, Irizarry R, Leisch F, Li C, Maechler M, Rossini AJ, Sawitzki G, Smith C, Smyth G, Tierney L, Yang JY, Zhang J: Bioconductor: open software development for computational biology and bioinformatics. Genome Biol 2004, 5:R80.

46. Benjamini $Y$, Hochberg $Y$ : Controlling the false discovery rate: $\mathbf{A}$ practical and powerful approach to multiple testing. J Royal Stat Soc 1995, 57B:289-300.

47. Yang YH, Speed T: Design issues for cDNA microarray experiments. Nat Rev Genet 2002, 3:579-588.

48. Bradford MM: A rapid and sensitive method for the quantitation of microgram quantities of protein utilizing the principle of protein-dye binding. Anal Biochem 1976, 72:248-254

49. Azevedo RA, Alas RM, Smith RJ, Lea PJ: Response of antioxidant enzymes to transfer from elevated carbon dioxide to air and ozone fumigation, in the leaves and roots of wild-type and a catalase-deficient mutant of barley. Physiol Plant 1998, 104:280-292.

50. Vitoria AP, Lea PJ, Azevedo RA: Antioxidant enzymes responses to cadmium in radish tissues. Phytochemistry 200I, 57:701-710.
Publish with BioMed Central and every scientist can read your work free of charge

"BioMed Central will be the most significant development for disseminating the results of biomedical research in our lifetime. "

Sir Paul Nurse, Cancer Research UK

Your research papers will be:

- available free of charge to the entire biomedical community

- peer reviewed and published immediately upon acceptance

- cited in PubMed and archived on PubMed Central

- yours - you keep the copyright

Submit your manuscript here:

http://www.biomedcentral.com/info/publishing_adv.asp
BioMedcentral 